should be used when using vasopressin beyond 24 hours, because significant hyponatremia may ensue.

\section{References}

1. Morales DL, Gregg D, Helman DN, Williams MR, Naka Y, Landry DW, et al. Arginine vasopressin in the treatment of 50 patients with postcardiotomy vasodilatory shock. Ann Thorac Surg. 2000;69:102-6.

2. Rosenzweig EB, Starc TJ, Chen JM, Cullinane S, Timchak DM, Gersony WM, et al. Intravenous arginine-vasopressin in children with vasodilatory shock after cardiac surgery. Circulation. 1999;100(19 Suppl):II182-6.

3. Walker BR, Haynes JJr, Wang HL, Voelkel NF. Vasopressin-induced pulmonary vasodilation in rats. Am J Physiol. 1989;257(2 Pt 2):H415-22.

4. Evora PR, Pearson PJ, Schaff HV. Arginine vasopressin induces endothelium-dependent vasodilatation of the pulmonary artery: V1-receptormediated production of nitric oxide. Chest. 1993;103:1241-5.

5. Eichinger MR, Walker BR. Enhanced pulmonary arterial dilation to arginine vasopressin in chronically hypoxic rats. Am J Physiol. 1994; 267(6 Pt 2):H2413-9.

\title{
Extended pericardiotomy avoids cardiopulmonary bypass during bilateral sequential lung transplantation
}

\author{
Takahiro Oto, MD, Marc Rabinov, FRACS, Franklin Rosenfeldt, FRACS, and \\ Donald S. Esmore, FRACS Melbourne, Australia
}

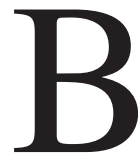

ilateral-sequential lung transplantation (BSLTx) through a clamshell thoracotomy has made the procedure of double-lung replacement possible without the use of cardiopulmonary bypass (CPB). ${ }^{1}$ Avoiding CPB has the potential advantages of reducing early allograft dysfunction $^{2}$ and coagulopathy, as well as lessening the amount of blood transfusion. ${ }^{3} \mathrm{CPB}$ is always required during lung transplantation for pulmonary hypertensive lung diseases or nonpulmonary hypertensive lung diseases with concomitant cardiac repair. However, $\mathrm{CPB}$ is also occasionally required during lung transplantation for inadequate gas exchange, right-heart dysfunction, or hemodynamic instability caused by mediastinal manipulation during single-lung ventilation. ${ }^{2}$ For patients with pulmonary fibrosis $(\mathrm{PF})$ undergoing BSLTx, adhesions and reduced size of the pleural space might necessitate forceful mediastinal manipulation to access the left hilum. This might cause severe hemodynamic compromise, despite inotropic support and inhaled nitric oxide. Unplanned CPB might be required, especially when the patients with $\mathrm{PF}$ have preexisting pulmonary hypertension ( $\mathrm{PH})$. To avoid hemodynamic instability during mediastinal manipulation, we postulated that extending the pericardiotomy might release the right

\footnotetext{
From the Department of Cardiothoracic Surgery, The Alfred Hospital, Monash University, Melbourne, Australia.

Received for publication June 16, 2004; revisions received June 24, 2004; accepted for publication June 30, 2004.

Address for reprints: Takahiro Oto, MD, Heart and Lung Transplant Unit, The Alfred Hospital, Commercial Road, Melbourne 3004, Australia (Email: takahirooto@aol.com).

J Thorac Cardiovasc Surg 2005;129:466-7

$0022-5223 / \$ 30.00$

Copyright $\odot 2005$ by The American Association for Thoracic Surgery

doi:10.1016/j.jtcvs.2004.06.045
}

heart from compression, improve cardiac function, and avoid the necessity of CPB. We have performed this procedure in 3 patients with moderate $\mathrm{PH}$ caused by $\mathrm{PF}$ and succeeded in all 3 in avoiding the unplanned use of CPB.

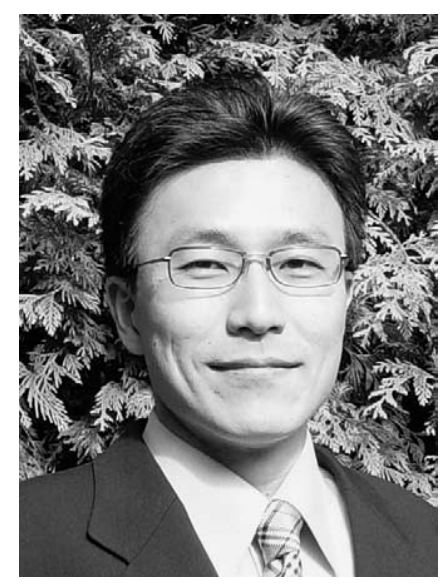

Dr Oto

\section{Clinical Summary}

Between March 1990 and May 2004, a total of 500 lung transplantations were performed at the Alfred Hospital, and of these, 239 were BSLTx procedures (Figure 1). Six of 21 patients with PF had severe preexisting $\mathrm{PH}$; that is, the ratio of pulmonary artery pressure (PAP) to systemic blood pressure (PAP/AoP) was more than 0.8 , and planned $\mathrm{CPB}$ was performed. For the 15 patients with moderate $\mathrm{PH}(\mathrm{PAP} / \mathrm{AoP}$ ratio of $<0.8), \mathrm{CPB}$ was on standby in the operating room and was initiated when needed. All 15 patients had an acceptable hemodynamic status approximately 10 minutes after clamping of the left pulmonary artery. All 10 patients with PAP/ AoP ratios of less than 0.5 did not require CPB to complete the procedure. For the 5 patients with $\mathrm{PAP} / \mathrm{AoP}$ ratios of between 0.5 and 0.8 (Table 1), severe hemodynamic instability resulted from mediastinal manipulation to access the left hilum and pulmonary ligament during the left-side procedure. Efforts made to avoid CPB included use of inotropic drug infusions (epinephrine or norepinephrine up to $2.5 \mu \mathrm{g} \cdot \mathrm{kg}^{-1} \cdot \mathrm{min}^{-1}$ ), vasodilators (sodium nitroprusside, nitroglycerin, or prostacyclin), and inhaled nitric oxide (40 ppm). Despite these treatments, PAP and central venous pressure increased with decreased $\mathrm{AoP}$ in all 5 patients, and initiation of $\mathrm{CPB}$ seemed to be unavoidable to complete the procedure. In the first 2 patients of this series, CPB was immediately initiated; however, in the last 3 patients, we elected to perform a longmidline pericardiotomy. The midline pericardiotomy extended to- 


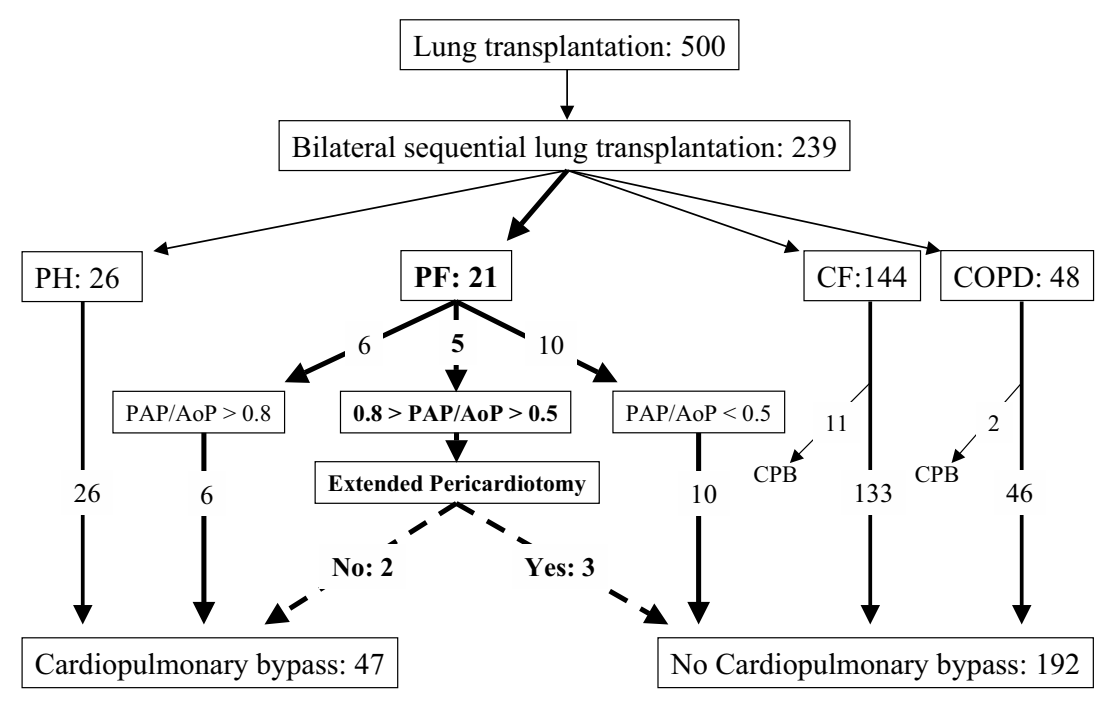

Figure 1. Algorithm of the patients undergoing bilateral sequential lung transplantation. PH, Primary pulmonary hypertension and Eisenmenger syndrome; $P F$, pulmonary fibrosis; $C F$, cystic fibrosis; COPD, chronic obstructive pulmonary disease; $C P B$, cardiopulmonary bypass.

TABLE 1. Profile of 5 patients with moderate preexisting pulmonary hypertension

\begin{tabular}{|c|c|c|c|c|c|c|c|c|c|}
\hline Case no. & Age/Sex & PAP/AoP ratio & $\begin{array}{l}\text { Perfusion scan } \\
\text { (right/left) }\end{array}$ & First lung & $\begin{array}{l}\text { RVEF } \\
(\%)\end{array}$ & $\begin{array}{l}\text { LVEF } \\
(\%)\end{array}$ & $\begin{array}{l}\text { Nitric } \\
\text { oxide }\end{array}$ & $\begin{array}{c}\text { Extended } \\
\text { pericardiotomy }\end{array}$ & $\begin{array}{l}\text { Unplanned } \\
\text { CPB }\end{array}$ \\
\hline 1 & $58 / \mathrm{M}$ & $65 / 100(0.65)$ & $69 / 31$ & Left & 71 & 66 & Yes & No & Yes \\
\hline 2 & $56 / \mathrm{M}$ & 66/91 (0.73) & $39 / 61$ & Right & 52 & 75 & Yes & No & Yes \\
\hline 3 & $35 / F$ & $45 / 80(0.56)$ & $52 / 48$ & Left & 55 & 55 & Yes & Yes & No \\
\hline 4 & $49 / M$ & $68 / 100(0.68)$ & $64 / 36$ & Left & 31 & 69 & Yes & Yes & No \\
\hline 5 & $34 / F$ & $70 / 100(0.70)$ & $51 / 49$ & Right & 46 & 56 & Yes & Yes & No \\
\hline
\end{tabular}

$P A P / A o P$, Systolic pulmonary arterial blood pressure relative to systemic blood pressure; $R V E F$, right ventricular ejection fraction; $L V E F$, left ventricular ejection fraction; $C P B$, cardiopulmonary bypass.

ward the inferior vena cava to a point $2 \mathrm{~cm}$ above the phrenic nerve. The heart was then displaced so that the right side of the heart was fully outside the pericardial cavity and in the right pleural space. The procedure to the left side was then recommenced. The hemodynamics then became stable, allowing the reduction of inotropic support and completion of the procedure without CPB. At the completion of the procedure, all 3 patients with extended pericardiotomies were rapidly weaned from inotropic support in the intensive care unit and were free from cardiac complications after BSLTx.

\section{Discussion}

Patients with PF are usually affected with various degrees of $\mathrm{PH}$. Pulmonary artery clamping reduces the available pulmonary vascular bed and increases right ventricular afterload. In turn, this can lead to right-heart failure, and this is emphasized by subsequent manipulation of the heart during the operative procedure. This phenomenon is usually seen during the procedure for implanting the first lung but also occasionally during the procedure for implanting the second lung as a result of early dysfunction of the already implanted lung. Further exposure of the left hilum through extension of the skin incision is not usually effective in overcoming the problem. The clamshell thoracotomy itself stretches the pericardium vertically and compresses the heart. When the heart is fixed in the pericardium, heart manipulation might disturb filling of the right heart; however, extended pericardiotomy allows the right heart to dilate and respond better to the increase in afterload.

We believe that the extended pericardiotomy is simple, effective, and a useful option to avoid the unplanned use of CPB during BSLTx with cardiac compression and merits further evaluation.

\section{References}

1. Kaiser LR, Pasque MK, Trulock EP, Low DE, Dresler CM, Cooper JD. Bilateral sequential lung transplantation: the procedure of choice for double-lung replacement. Ann Thorac Surg. 1991;52:438-45.

2. McRae K. Con: lung transplantation should not be routinely performed with cardiopulmonary bypass. J Cardiothorac Vasc Anesth. 2000;14: 746-50.

3. Gayes JM, Giron L, Nissen MD, Plut D. Anesthetic considerations for patients undergoing double-lung transplantation. J Cardiothorac Vasc Anesth. 1990;4:486-98. 